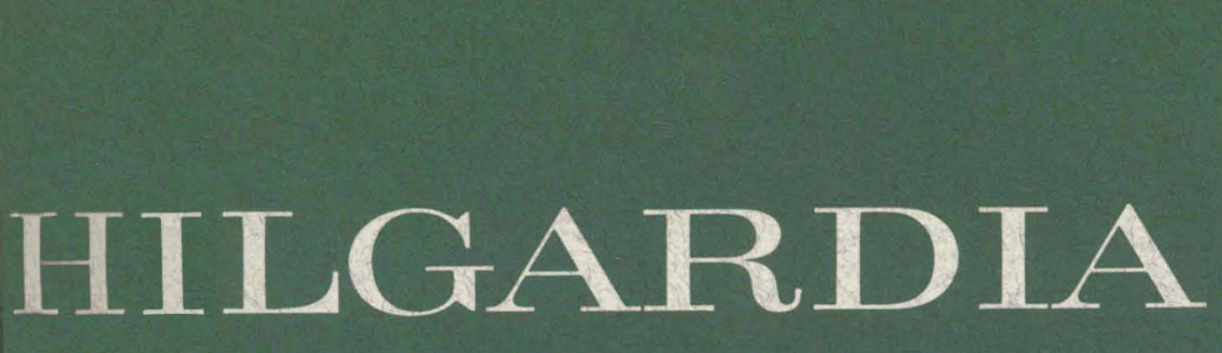

A JOURNALOF AGRICULTURAL SCIENCE PUBLISHED BY THE CALIFORNIAAGRICULTURAL EXPERIMENTSTATION

Volume 40, Number 8 - August, 1970

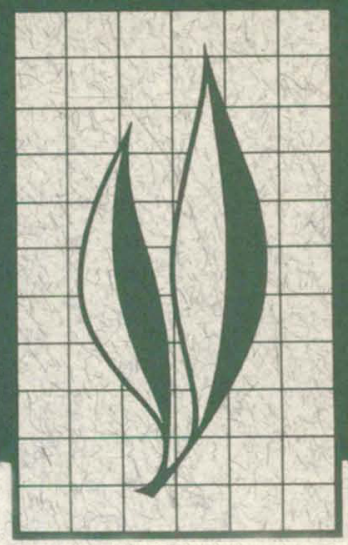

\title{
Strength Characteristics of Fruit Tree Bark
}

R. B. Fridley, G. K. Brown, and P. A. Adrian 


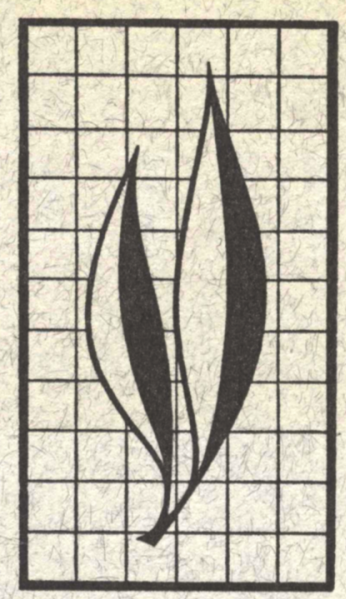

Mechanical harvesting of fruit trees by shaking their primary limbs or trunks has sometimes been responsible for injury to the trees at the point where shaking equipment is attached. Such injuries often result in infection by the fungus Ceratocystis fimbriata. In the present study, research was conducted to determine the strength of tree bark so as to evaluate its ability to resist injury caused by forces applied radially, tangentially, or longitudinally to the limb. The maximum radial stress which could be exerted on the bark of trees tested without damage which can lead to Ceratocystis canker was found to be in the range of 500 to 1000 psi, whereas the maximum tangential and longitudinal stresses were only about one-third or one-fourth as strong. Low strengths were generally associated with high moisture conditions, young tree age, and growing cambium.

\section{THE AUTHORS:}

R. B. Fridley is Professor of Agricultural Engineering and Agricultural Engineer in the Experiment Station, Davis; G. K. Brown is Agricultural Engineer in the Agricultural Engineering Research Division, Agricultural Research Service, United States Department of Agriculture, Riverside; P. A. Adrian is Agricultural Engineer in the Agricultural Engineering Research Division, Agricultural Research Service, United States Department of Agriculture, Salinas. 


\section{Strength Characteristics of Fruit Tree Bark ${ }^{1}$}

\section{INTRODUCTION}

IN RECENT YEARS, several types of tree fruits have been mechanically harvested with tree shakers attached to the primary limbs or the trunks of trees. Attachment is made by a clamp which transmits clamping and shaking forces to the tree through the bark. This sometimes damages the bark, and though the damage itself is usually not lethal it can result in a canker disease caused by a fungus (Ceratocystis fimbriata) which causes the limb or tree to die prematurely (DeVay et al. 1960). The disease is potentially serious on almonds, peaches, prunes, and apricots (DeVay et al. 1962). When the bark is damaged insects may carry fungi to the injured area, which provides a favorable environment for fungus development and subsequent cankers. Infection and spreading of cankers is closely related to temperature and soil moisture; infection does not occur in winter and cankers spread very slowly, but activity is much greater in summer and cankers expand rapidly. The process is further accelerated if the injury occurs a week or two after irrigation.

Preliminary observations indicated that the amount of bark injury varied greatly from orchard to orchard, and that injury was caused in a number of ways. It was sometimes caused simply by clamping onto the limb; at other times it occurred during shaking. In some instances, the cause of injury was inherent in the design of the clamp. In others, it was caused by poor operation, such as not properly centering the clamp on the limb, or by clamping too firmly, which resulted in excessive radial stresses. Longitudinal stresses which arose when the shaking force was not perpendicular to the limb also caused injury.

From an engineering standpoint it is necessary to know the magnitude of bark-strength properties, and the effect of environmental and plant condition factors on them, in order to design shaker clamps which minimize bark damage (Adrian and Fridley, 1964). Such information is also of value in properly controlling conditions influencing bark strength.

The physiological condition of the cambium has an appreciable effect on bark strength. During reactivation in the spring, cells in the cambial layer swell and enlarge in the radial direction, the radial walls become thinner and the cell contents seem to change from a solid to a liquid consistency (Priestley, 1930). All the tissue in the cambial zone appears as a translucent ring in which intercellular spaces are free of air and saturated with water. As soon as this stage is reached, the cambial walls break readily and the bark "slips" over the wood. ("Slip" is used to describe the ability to peel bark from the limb with a smooth separation in the cambial zone.) As cell division takes place, the bark continues to slip

\footnotetext{
${ }^{1}$ Submitted for publication April 12, 1970.
} 
(Esau, 1948). Cessation of cambial activity occurs in fall or before a normal rest period. During the period of cambial dormancy which follows, the bark and cambium are low in moisture and cell walls are thickened (Evert, 1958). Dormant cambium is tough and slip does not occur at this time.

Cessation of cambial activity and shrinkage of the cambial cells (similar to deactivation) during a normal growth period apparently can be caused by a lack of moisture. Following a period of hot, dry weather during which no irrigation water was applied, the cambium of oranges was not active and slip did not occur (Schneider, 1952). Shortly after an irrigation, two out of five trees showed renewed cambial activity and the bark again slipped.

\section{OBJECTIVES}

The primary goal of this study was to determine the maximum stresses that could be applied to trees without causing harmful bark injury. To do this, the effects of moisture, tree age, variety, species, and growth cycle were investigated. The ability of limbs and bark to withstand the following types of stresses was also measured and studied.

Radial stress. This is a compressive stress exerted on bark surface radial to the limb.

Tangential shear stress. This occurs between bark and wood at the cambium and in a direction tangential to limbs.

\section{TEST PROCEDURES AND EQUIPMENT}

\section{Field tests}

The tester shown in figure 1 was designed for field application of radial stress or total tangential stress on bark. The tester is shown with pads in contact with the tree for application of radial stress. Force was applied by the hydraulic cylinder in the background. The pad on the cylinder was 1 inch in diameter; the pad on the arm opposite the cylinder was 0.71 inch in diameter to provide a method of checking the possible effect of contact area on the stress causing bark injury. For tangential tests, the two shear pads were first drawn against the tree by a hydraulic cylinder which replaced the arm in the foreground and tangential force was applied by the cylinder shown. The
Total tangential stress. This is exerted on bark surface tangentially to the limb and transmitted to adjacent bark by shear, tensile, and compressive stresses in the bark; it includes the tangential shear stress.

Longitudinal shear stress. Shear stress occurs between the bark and wood at the cambium in a direction longitudinal to limbs.

Tensile stress. Tensile stress occurs in bark tissue in a direction longitudinal or tangential to the limb.

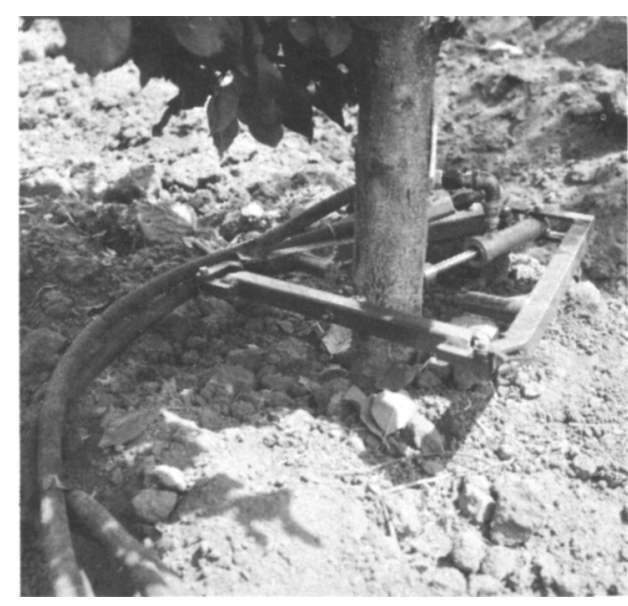

Fig. 1. Bark tester in use. A pad for applying radial compression is in contact with bark; another is hidden by the tree. Pads for applying tangential stress are not in contact. 
shear pads are 1 inch in diameter and are knurled to minimize slippage on bark; a normal stress of 150 to 225 psi exerted on the tree by the pads was required to keep them from slipping over the bark surface. Stresses applied to the tree were determined by recording hydraulic pressures developed by a hand-driven pump (fig. 2).

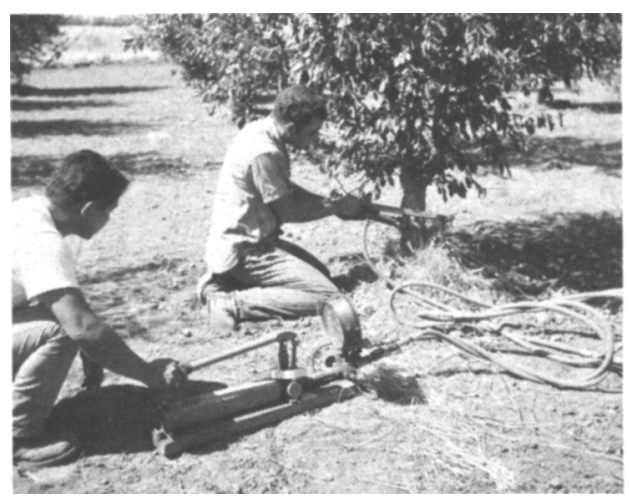

Fig. 2. Bark test on trunk of young prune tree, showing hand-driven hydraulic pump used to actuate tester.

Originally, a rubber disc was placed under each pad to distribute the load for radial tests. During preliminary tests, however, the rubber was found to flow out from under the pads and stresses resulting from this caused the bark under the center of the rubber to split longitudinally with the limb; cork discs reduced this problem, but three mill mylar (3/1000 of an inch thick) placed between the rubber pads and the bark was even more satisfactory. A thin section of mylar reduced tangential flow, the slick surface of mylar minimized the transmission of tangential forces to the tree, and the rubber permitted distribution of force over the desired area. Results on almond limbs showed that injury occurred at a stress 50 psi lower without mylar than with mylar. Therefore, a combination of mylar and rubber was used in all subsequent field tests.

Radial tests were conducted on several species and varieties. Correlation of visible injury and infection by Ceratocystis canker was determined during tests on French prunes; all other tests were evaluated on the basis of visible injury alone. Visible injury was determined by careful observation of the test area and inspection of the cambium after a small piece of bark had been carefully removed from the area.

Tangential tests were conducted initially for comparison with radial tests. Because trees were most susceptible to tangential failure, these tests were used most extensively for field evaluation of the effects of irrigation, tree age, and tree variety and species. Total tangential stress (including tension, compression, and shear reactions in the bark as well as shear in the cambial zone) was used primarily. Some tests were conducted to determine tangential shear strength of the cambial zone exclusive of tension, compression, and shear in the bark. This was accomplished by careful cutting through bark around the perimeter of the test area and removing all bark adjacent prior to testing. The later test was not used extensively because of excessive time required.

\section{Laboratory tests}

Laboratory tests were conducted on limb sections using a Dillon Model M Low Range Universal Tester with the test jig shown in figures 3 and 4. The tests were to determine longitudinal shear strength between bark and limb, and to study how bark moisture and radial stress effect this strength. Limbs selected were nearly round, straight, and-free of secondary growth in the section to be tested. Limbs with mechanical, sun, insect, or disease damage were not used. All limbs used were pruned of secondary growth and cut from the tree between 8:00 and 9:00 A.M. Several cylindrical sections 3 inches long were cut from the limb and sealed with melted wax. The average bark moisture of these sealed sections 
changed less than 1 per cent during the complete test period ( 4 to 6 hours) even without special environmental control. Several shear tests were made on each limb section.

Test areas were prepared by cutting around an area approximately 1 inch square; surrounding tissue was cut away and saved for moisture determinations. Surface bark was sanded lightly to remove loose tissue and dirt

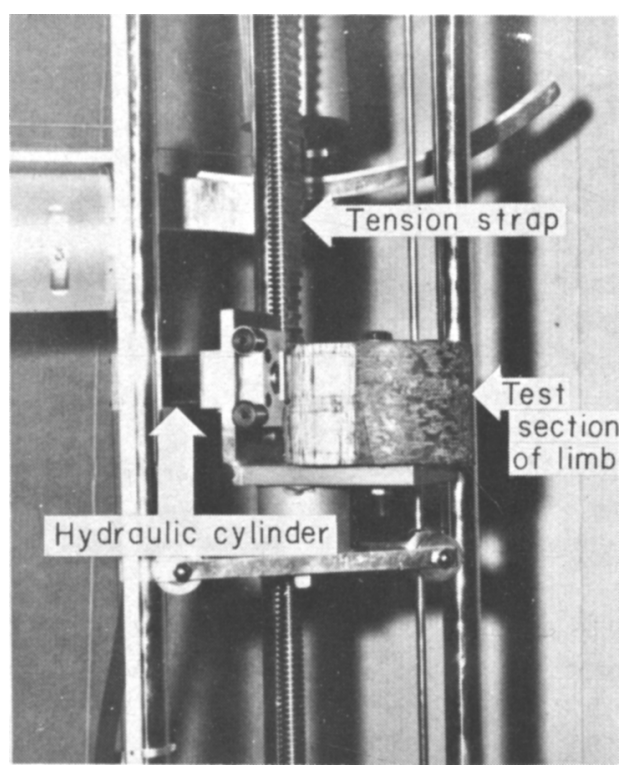

Fig. 3. Laboratory test equipment for applying longitudinal and radial stresses. The tension strap applies longitudinal stress, and the hydraulic cylinder applies radial stress.

and then coated with a catalyst for Eastman 910 contact cement. One end of a tension strap made from a thin, steel-cable reinforced timing belt 1 inch wide was coated with Eastman 910 contact cement and pressed against the bark. Radial stress was applied by a hydraulic cylinder fitted with a $11 / 4 \times$ 11/4-inch rubber-covered curved steel pad. The rubber pad was $7 / 32$-inch-thick neoprene of 50 durometer hardness on a Shore type A meter; two sheets of 0.014 -inch thick teflon were used between the rubber pad and the tension strap to minimize any effects due to tangential flow of the rubber pad. After the test area was prepared, the limb section was aligned and secured in the tester; the desired radial stress was applied and then shear force was applied at a rate of 0.70 inches per minute. The shear force and radial stress at failure were recorded, as was the location of failure (i.e., in the cambial zone or in the bark). Each test area was numbered and later measured.

Occasionally, the bottom or sides of a test area would peel loose during the test because of uneven surfaces or other conditions; this resulted in non-uniform pressure distribution over the test area. Peeled or initially loose areas could be easily observed (and measured) shortly after tests because these areas had a greater degree of browning (oxidation) in the cambial surface. The gross test area was used in calculating radial stress at failure; but the net test area (gross area minus peeled or loose area) was used in calculating ultimate shear stress.

Measurement of bark strain (deformation) associated with longitudinal shear stress was made with a displacement transducer (fig. 4). Displacement was recorded continuously by readings taken at 10-pound increments. By measuring bark thickness $(L)$ and bark displacement $\left(e_{s}\right)$, a bark strain (inches deformation per inch thickness) value $\left(e_{s} / L\right)$ could be calculated for each force value.

Ultimate tensile strength of bark was determined by carefully removing 1inch by 3 -inch strips of bark from the limb. Tension straps were glued to a 1 inch length of bark on each end of the bark strip. The glued joints were then clamped to prevent peeling of the outer bark and tensile force was applied to the straps.

\section{Bark moisture determination}

Moisture contents of bark were used as measurements in field and laboratory tests. A sample of at least $1 \frac{1}{2}$ grams of 


\section{Shear force}

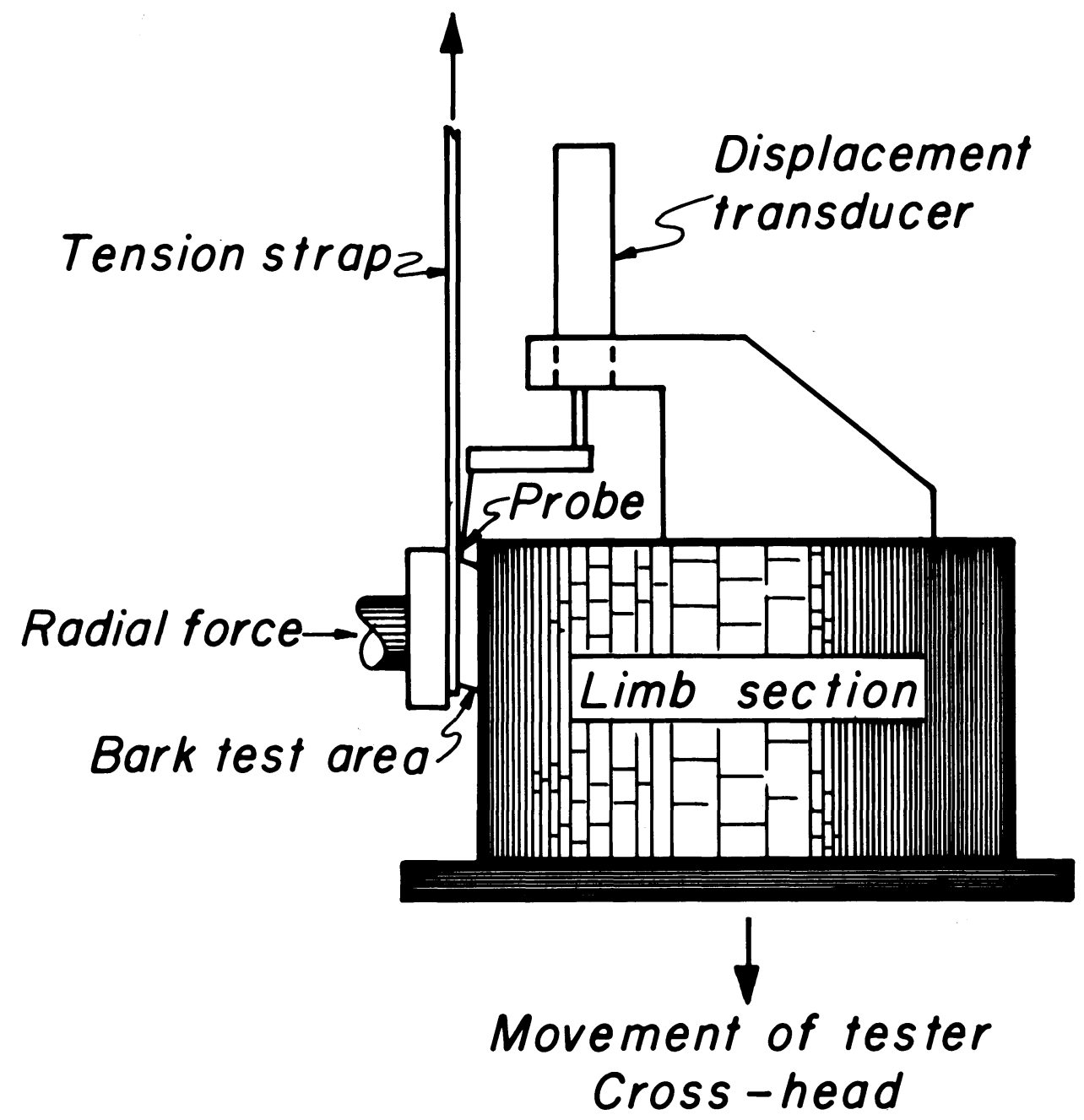

Fig. 4. Schematic diagram of equipment used for bark-strain measurement.

bark adjacent to each test area was taken to the depth of the cambial zone prior to the test, and immediately placed in a metal can and sealed with plastic tape. This method was quick and much simpler than using only tissue from the cambial zone or from an inner part of bark tissue near that zone.

After samples were weighed, they were uncovered and dried in a forced draft oven at $55^{\circ} \mathrm{C}$. for 48 hours-this prevented loss of volatiles or charring of organic material. A drying time of 48 hours was found adequate for even the highest moisture conditions, as calculated moisture content did not change by more than 0.5 per cent during the following 12 hours. Moisture values were also used to indicate a relative difference in moisture conditions, and therefore an exact moisture content was not necessary. 


\section{RESULTS AND DISCUSSION}

\section{Susceptibility to infection}

Preliminary field tests made to determine the effect of applying excessive radial stress on the bark of trees revealed discoloration in inner bark when stress exceeded some value. As stress increased, discoloration extended to the cambium and discoloration increased with increase in force (fig. 5, table 1). Apparently, when stress caused hairline cracks, air entered-and this caused oxidation which was visible as browning when bark samples were cut

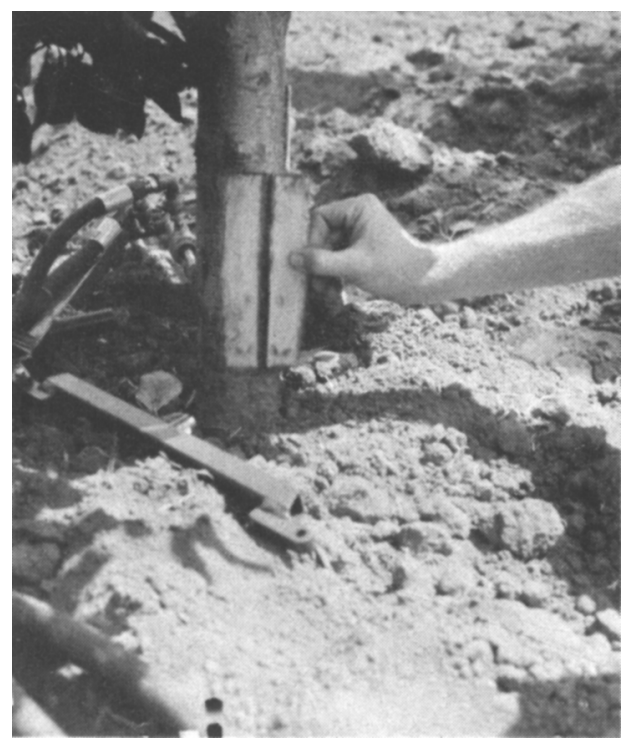

Fig. 5. Test area showing discoloration occurring at cambium with application of high radial stresses. Four tests were conducted on the strip, with stress increasing top to bottom. Note discoloration in lower two test areas.

from the tree. When browning occurred, the inner bark had a porous, degenerative appearance.

Tests were conducted on almonds to determine the effect of different contact areas on the radial stresses causing discoloration. Contact areas of 0.4 to 7.5 square inches were tested; small areas were obtained with the field tester described and large areas were obtained with a shaker clamp. Contact areas had no appreciable effect on the stress causing browning at the cambium. Stresses were in the range of 575-600 psi for all contact areas. This indicated that stress concentration was not a problem when using small pads-if stress concentration were a significant factor the average stress causing browning would be lower for the small contact areas. Browning did occur with stresses below 575 psi when there were small knots under the pads.

A number of tests were conducted to determine the relationship between visible injury and fungus infection. Several trees were subjected to 12 different radial stresses on each of two limbs. Test areas on one limb were cut open to determine when darkening occurred; areas on the second limb were inoculated with the fungus spores and wrapped with masking tape. Ceratocystis canker infection occurred on 20-year-old prune trees when the radial stress exceeded 1000 psi (table 1). This corresponded very closely to the magnitude of stress which visibly cracked bark to the cambium. On young trees, critical stresses were about 75 per cent of this value.

During field tests of total tangential shear stress, injury and infection occurred only when the bark failed completely. Injury was a complex type of failure, including shear failure at the cambium and a tensile failure of the bark fibers. Tensile failure was both perpendicular and longitudinal to the bark fibers.

\section{Relative importance of radial, tangential, and longitudinal stresses}

Table 2 compares radial stresses causing browning at the cambium and tangential stresses causing failure in several species and varieties. Results given are from tests on two to six trees 
with six to twelve measurements per tree.

Results indicated that tangential shear strength contributes about 50 to 70 per cent of the total tangential strength. Figure 6 shows typical results of tests on 11-year-old French prune trees. Where bark was observed to slip easily, the contribution of shear strength was minimal.

TABLe 1

STRESSES CAUSING VISIBLE INJURY TO THE BARK

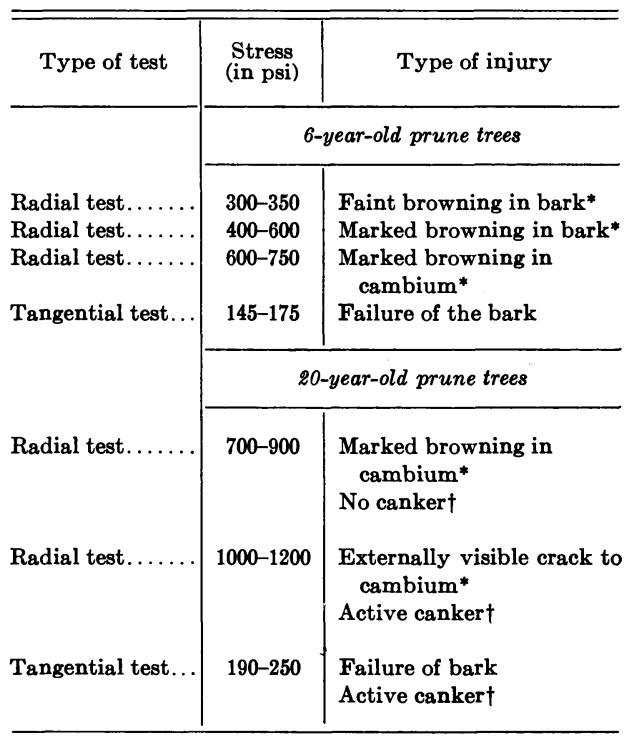

* Inspection made 5 minutes after test; longer intervals were unnecessary.

$\dagger$ Inspection made $21 / 2$ months after inoculation. No 6-year-old trees were inoculated.

Although data for providing a good direct comparison of longitudinal and tangential failure were not collected, it is known that both types of failure occur at approximately the same stress. Therefore, tangential or longitudinal stress causing failure is substantially less than radial stress causing browning of the cambium. This demonstrates that the application of forces having a component tangential to or longitudinal with the limb is a primary factor in bark injury.
TABle 2

COMPARISON OF RADIAL STRESS

CAUSING BROWNING AT CAMBIUM

AND TANGENTIAL STRESS CAUSING

FAILURE FOR VARIOUS SPECIES AND VARIETIES*

\begin{tabular}{|c|c|c|}
\hline Species and variety & $\begin{array}{c}\text { Radial } \\
\text { stress }\end{array}$ & $\underset{\text { stress }}{\text { Tangential }}$ \\
\hline & \multicolumn{2}{|c|}{$p s i$} \\
\hline Tilton apricots $\dagger$. & $800-900$ & $250-265$ \\
\hline Blenheim apricots $\nmid \ldots \ldots \ldots$ & $800-900$ & $215-245$ \\
\hline Dixon peaches........... & $700-800$ & $200-230$ \\
\hline Non Pariel almonds. . & $550-600$ & \\
\hline Peerless almonds.... & $550-600$ & \\
\hline French prunest.... & $600-750$ & $145-175$ \\
\hline French prunes... & $700-900$ & $190-250$ \\
\hline Olives.......... & $500-600$ & $140-160$ \\
\hline
\end{tabular}

* Results for each crop from tests on two to six tree with six to twelve measurements per tree.

† Trees approximately 6 years old; other trees tested were mature.

\section{Relationship of radial stress and bark moisture to longitudinal shear strength}

Figure 7 summarizes data from laboratory tests on the relationship between shear strength, radial stress, and bark moisture. Trees tested were 8year-old Drake almonds, 7-and-8-yearold Jordan almonds, and 8-and-12-yearold Mission olives. Laboratory tests were done between mid-August and early October. Figure 8 shows regression lines calculated for six of the tests in which the data gave a linear but scattered trend. All bark moisture is given on a dry-weight basis.

The first two tests on Drake almonds (fig. 7) were on a limb cut from a tree with top foliage left intact. The tree itself had been irrigated 7 weeks prior to the tests. Early in the day, about 18 inches of the lower part was cut into test sections and then sealed and tested (113 per cent moisture); the remaining portion was allowed to dry out by transpiration from the foilage until mid-afternoon, and then was sectioned, sealed, and tested (103 per cent moisture). At both moisture levels, shear failure occurred in the cambial zone 


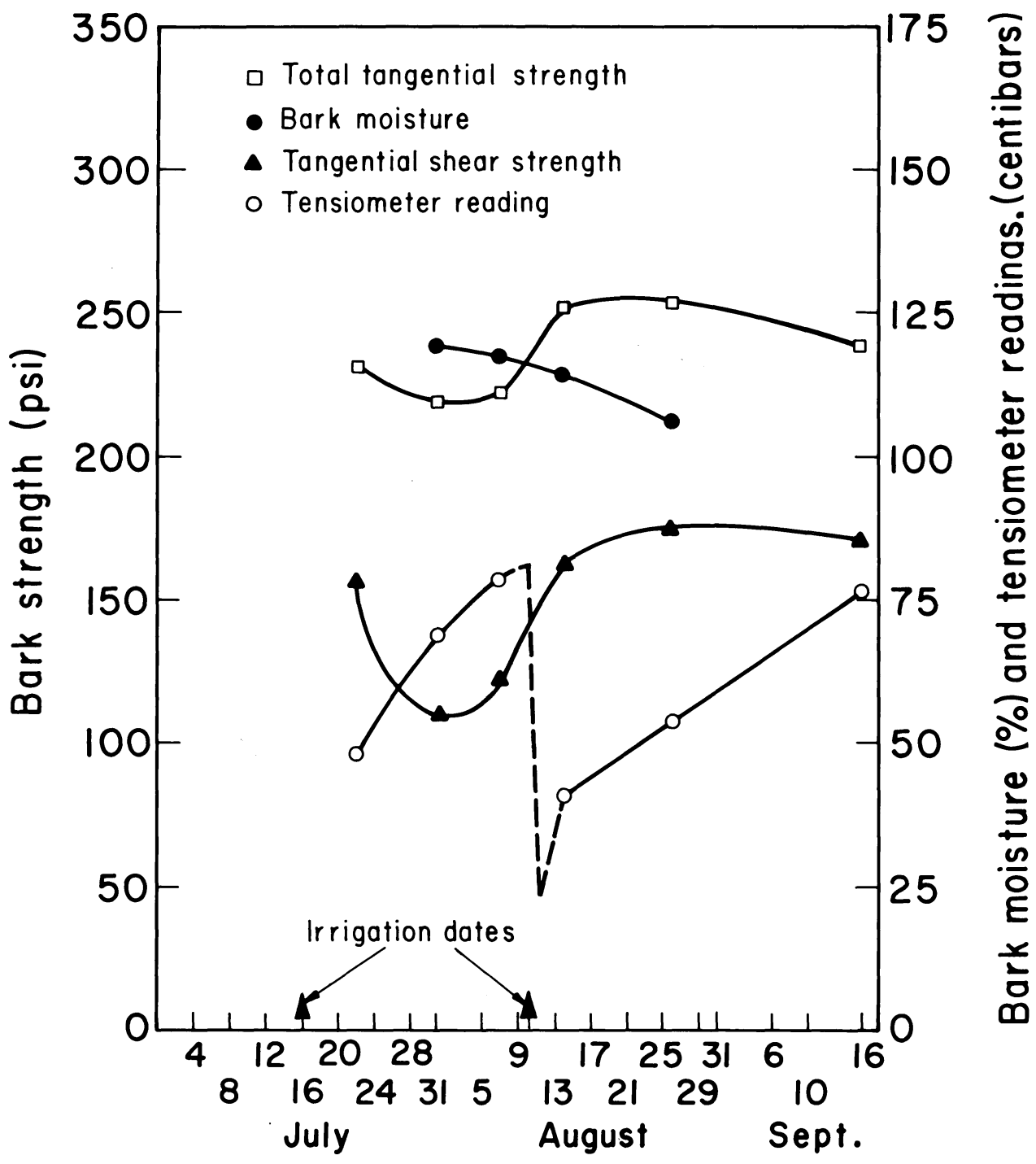

\section{Date}

Fig. 6. Comparison of total tangential strength and tangential shear strength of the bark of 11-year-old French prune trees. Moisture conditions of the soil and the bark as indicated by tensiometer readings are also known. Bark moisture is expressed on a per cent dry basis.

and bark slipped when peeled from the limb. The test at 96 per cent moisture was made 3 weeks later on a limb from the same block of trees which had been irrigated 3 weeks prior to this and harvested 3 to 5 days prior to the test. Leaf fall was heavy compared with that of trees on regular irrigation.
Shear failure in almost every test sample was located about halfway through the bark, rather than in the cambial zone. The bark did not slip when peeled from the limb, and a check of other limbs in these trees revealed that bark on all limbs behaved similarly.

The block of Drake almonds (fig. 7) 


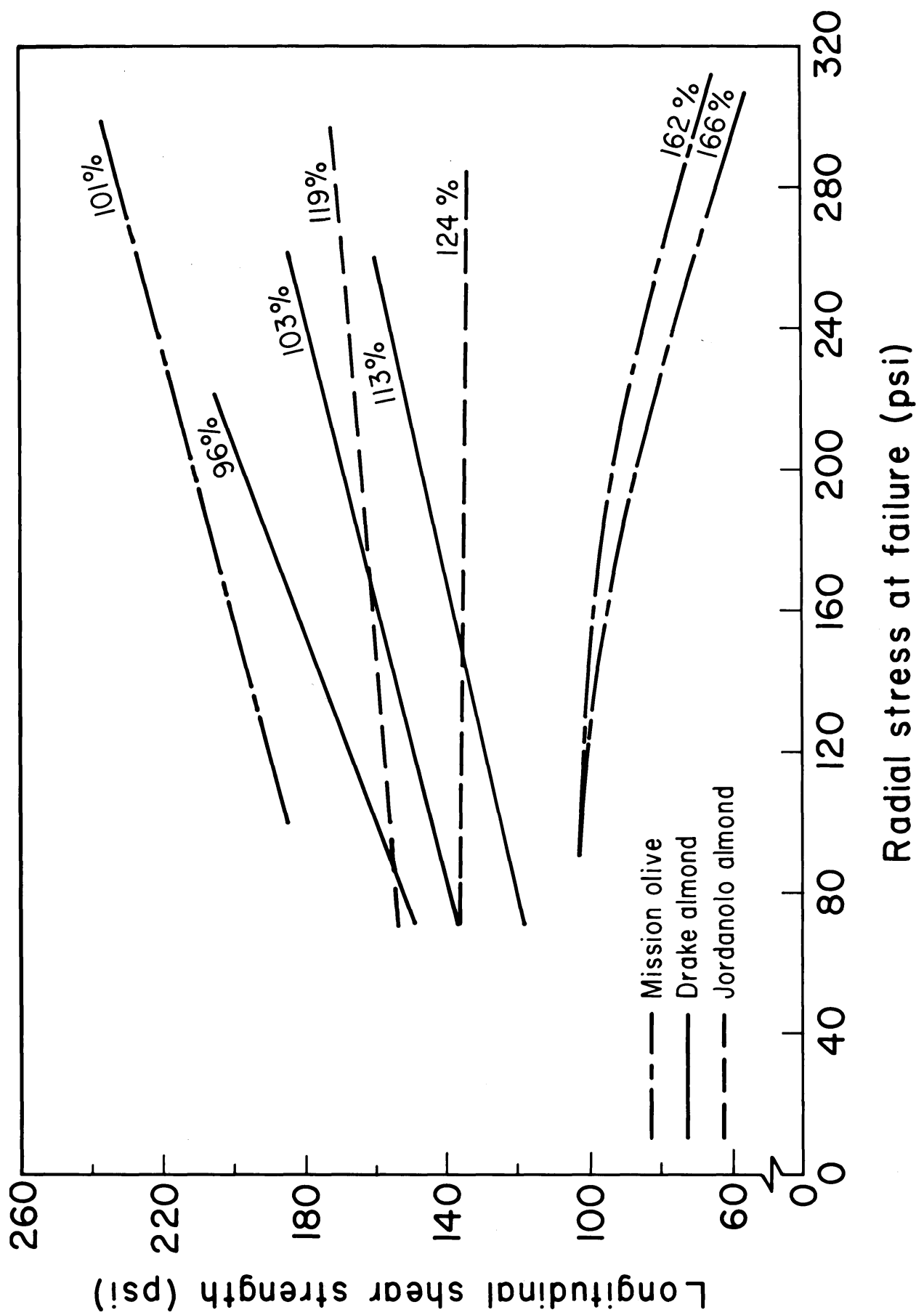

Fig. 7. Relationship of longitudinal shear strength of bark, radial strength, and bark moisture. Number adjacent to each line shows bark moisture expressed as per cent dry basis; non-linear curves were determined by calculating averages and fitting curve through average points. Limb diameters in test region were $3 \frac{3}{8}$ to $3 \frac{3}{4}$ inches. 


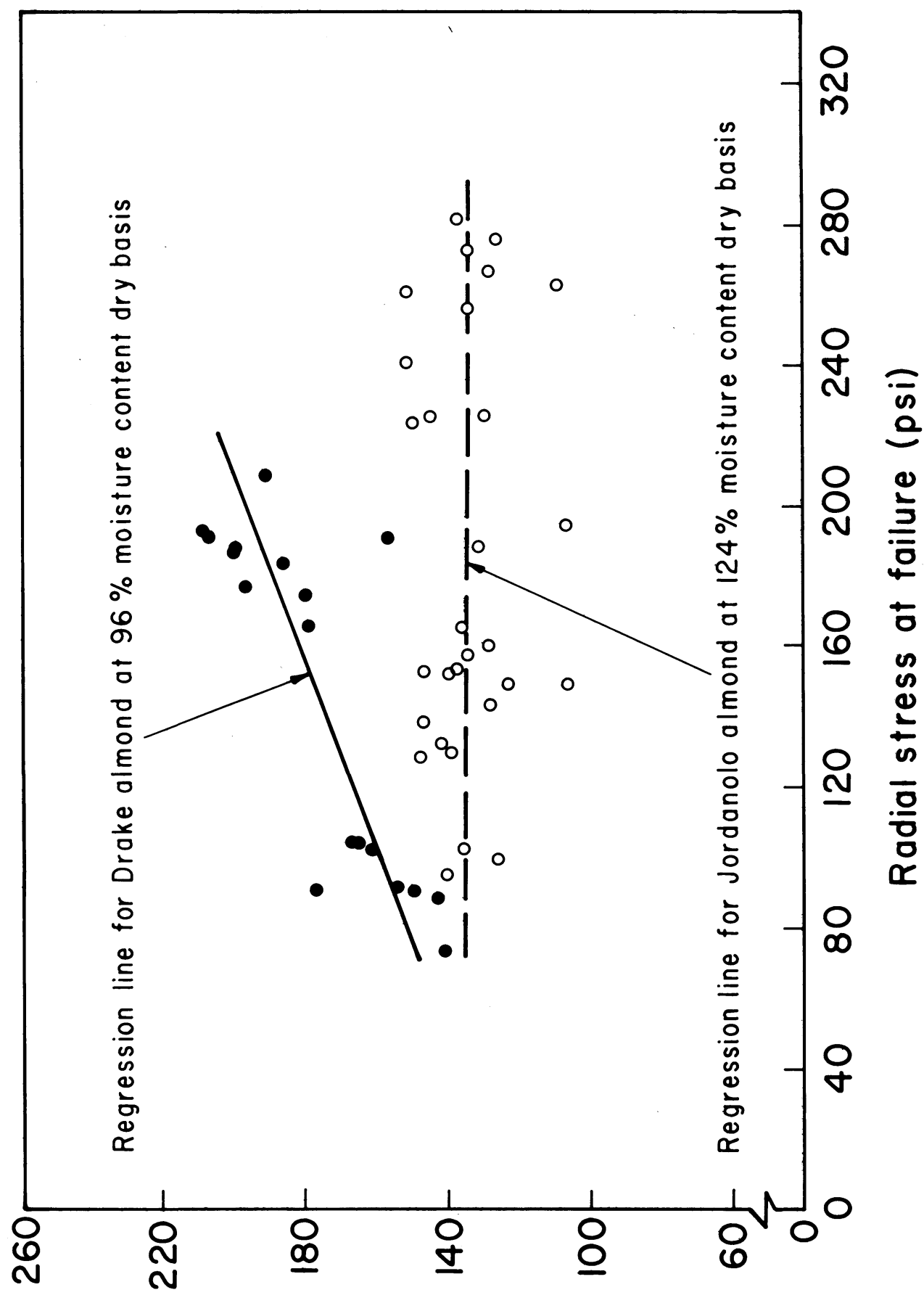

(!sd) 4łbuədts doəys jou!pnł!buo 7

Fig. 8. Relationship of longitudinal shear strength of bark and radial stress for Drake almonds at 96 per cent bark moisture and Jordanolo almonds at 124 per cent bark moisture, showing scatter of data and regression lines calculated for each test. 
had ceased to shear in the cambial zone, so a regularly irrigated block of Jorclanolo almond trees was tested (most limbs in this block would still slip). The test at 124 per cent moisture was made in mid-September, 3 to 5 days after an irrigation. Shear failure was in the cambial zone, and the bark slipped from the limb. The cambial zone was quite translucent. The test at 119 per cent moisture was made a week later. Shear failure again occurred in the cambial zone; the bark slipped from the limb, and the cambial zone appeared translucent.

Tests on Mission olives at 166 per cent and 162 per cent moisture were performed on September 24 and October 5 , respectively. Limbs were obtained from a block of 8-year-old trees which had been irrigated at regular intervals, the most recent irrigation being about September 12. Just before this irrigation the bark on most limbs would not slip. In both tests, shear failure was in the cambial zone, the bark slipped easily from the limb, and the cambial zone appeared soaked and translucent.

During the September 24 test, a leak developed in the hydraulic circuit which required using a higher initial radial stress to maintain desired radial stress at failure. To check the effect of a high initial radial stress, a brief compression test was conducted; this revealed that application of 350,400 , and 500 psi radial stresses would loosen 15 , 33 , and 100 per cent of the gross test area, respectively. Therefore, the September 24 results from tests with radial stresses of 260 to 350 psi were adjusted upward by calculating a new average shear strength based on the net shear area (fig. 10).

The test at 101 per cent moisture (fig. 7) were made September 28 on a limb from a block of 12-year-old trees which had not been irrigated for 5 to 6 weeks, and which had somewhat thicker bark than did the 8-year-old trees. The zone of shear failure on the older trees

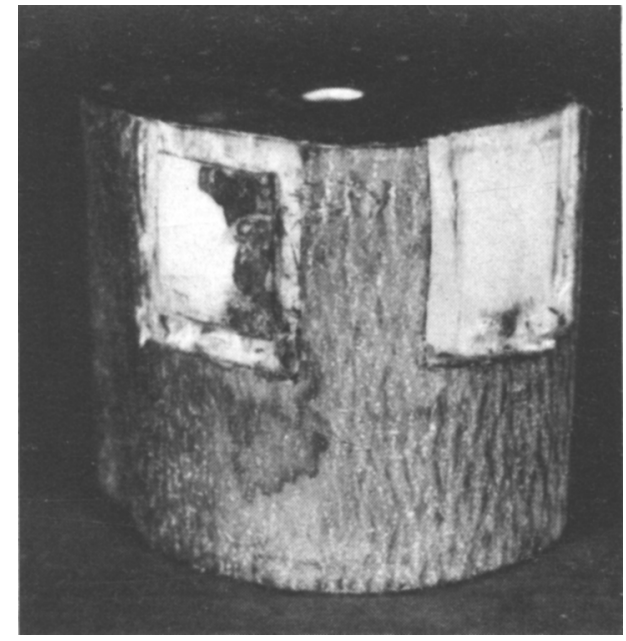

Fig. 9. Failure of olive bark at cambium (right), and within the bark near the surface (as shown on the left).

was about $1 / 4$ to $1 / 3$ of the way from the cambial zone into the bark tissue. The bark did not slip from the limb, and the cambial zone did not appear translucent or wet (the bark of similar age trees in a block which had been irrigated did slip).

The laboratory tests described (figs. 7,8 , and 10) show an increase in longitudinal shear strength as bark moisture decreased, and this effect was more pronounced as radial stress increased. In tests at highest moisture, strength decreased as the radial stress increased; in contrast, strength generally increased as radial stress increased at lower moisture. One test showed essentially no change in strength with an increase in radial stress for the range used.

The method of moisture determination used in these tests is not a direct indicator of the moisture condition at the cambium, because the value obtained is an average for bark having little cambium tissue-if cambium tissue alone were used, moisture content would have been higher. This method also introduces variations in moisture values because of differences in bark structure and composition. 


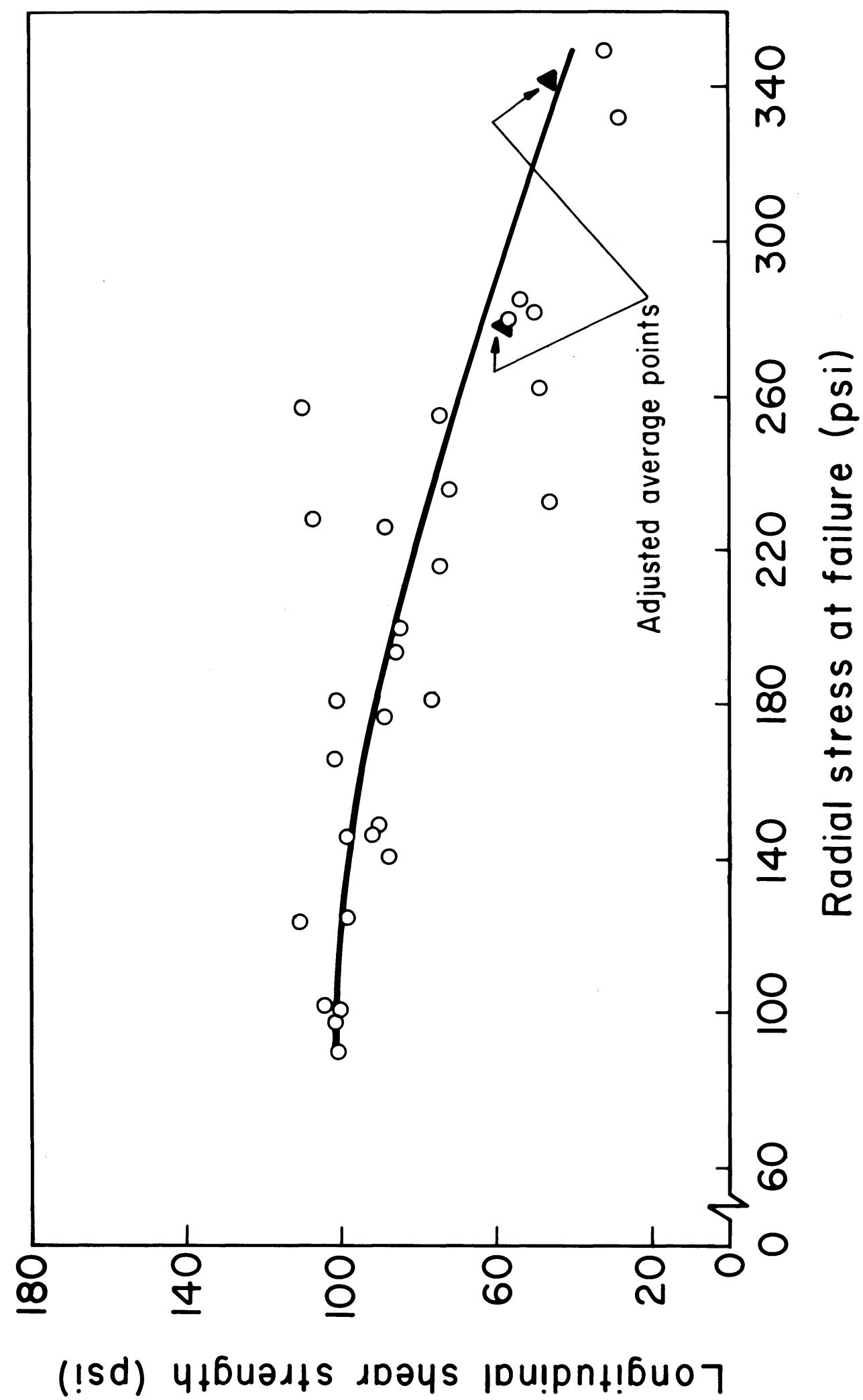

Fig. 10. Longitudinal shear strength of high moisture (166 per cent) Mission olive bark. Data at radial stresses of approximately 260 to 350 psi adjusted to account for the fact that high radial stresses loosened a portion of the gross test area of this high-moisture, easy-to-slip bark. 
TABLE 3

SEASONAL VARIATION OF BARK STRENGTH IN A DIRECTION LONGITUDINAL TO LIMBS

\begin{tabular}{|c|c|c|c|c|c|}
\hline \multirow{2}{*}{ Variety and species } & \multicolumn{5}{|c|}{ Longitudinal bark strength* } \\
\hline & $\begin{array}{c}\text { February- } \\
\text { March }\end{array}$ & May & July & $\begin{array}{l}\text { August- } \\
\text { September }\end{array}$ & $\begin{array}{c}\text { November- } \\
\text { January }\end{array}$ \\
\hline & \multicolumn{5}{|c|}{ psi } \\
\hline Texas almond ....... & 151 & 65 & 81 & 122 & 146 \\
\hline Texas almond........ & 141 & 59 & 93 & 121 & 172 \\
\hline French prune........ & 93 & 65 & 98 & 99 & 130 \\
\hline French prune.... & 81 & 66 & 89 & 114 & 153 \\
\hline French prune... & 100 & 71 & 97 & 117 & 121 \\
\hline Dixon peach..... & 140 & 74 & 79 & 94 & 133 \\
\hline
\end{tabular}

* Each number represents the average of several tests on a tree.

\section{Seasonal variation in longitudinal shear strength and bark moisture}

Laboratory tests were also conducted to determine seasonal variation in longitudinal shear strength. Table 3 shows the comparative bark strengths for three species throughout the year. The strength of most species was relatively high in November and January; by May all bark strengths had become low (59 to 74 psi), but strength then increased considerably (121 to $172 \mathrm{psi}$ ) from June to January. Reduction in bark strength from March to May was probably due mostly to reactivation of the cambium. In November, when the bark strength was again high, the trees were going dormant and the cambium was inactive.

There is no set pattern or trend to indicate that one species is stronger than another throughout the entire season. Variation in strength for any species apparently was governed by the time of testing in relation to the growing cycle. Bark moisture of the several species generally varied from one test date to another (table 4): again, this variation probably was related to the growth cycle-for example, moisture content of French prune bark ranged from a low of 69 per cent to a high of 144 per cent.

In November, December, and January the bark moisture of most deciduous trees was lowest and the bark was dry and stringy. In February there was generally a slight increase in bark moisture as buds began to swell. This renewal of growth may account for the slight difference in bark moisture between November-January and Febru-

Table 4

SEASONAL VARIATION OF BARK MOISTURE

\begin{tabular}{|c|c|c|c|c|c|}
\hline \multirow{2}{*}{ Variety and species } & \multicolumn{5}{|c|}{ Bark moisture } \\
\hline & $\underset{\text { March }}{\text { February- }}$ & May & July & $\begin{array}{l}\text { August- } \\
\text { September }\end{array}$ & $\begin{array}{c}\text { November- } \\
\text { January }\end{array}$ \\
\hline & \multicolumn{5}{|c|}{ per cent dry basis } \\
\hline Texas almond........ & 120 & 148 & 130 & 108 & 115 \\
\hline Texas almond ........ & 136 & 143 & 111 & 127 & 111 \\
\hline French prune........ & 106 & 144 & 115 & 115 & 115 \\
\hline French prune........ & 117 & 124 & 114 & 91 & 85 \\
\hline French prune........ & 87 & 122 & 91 & 82 & 69 \\
\hline Dixon peach......... & 102 & 112 & 108 & 98 & 97 \\
\hline
\end{tabular}




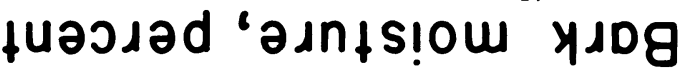

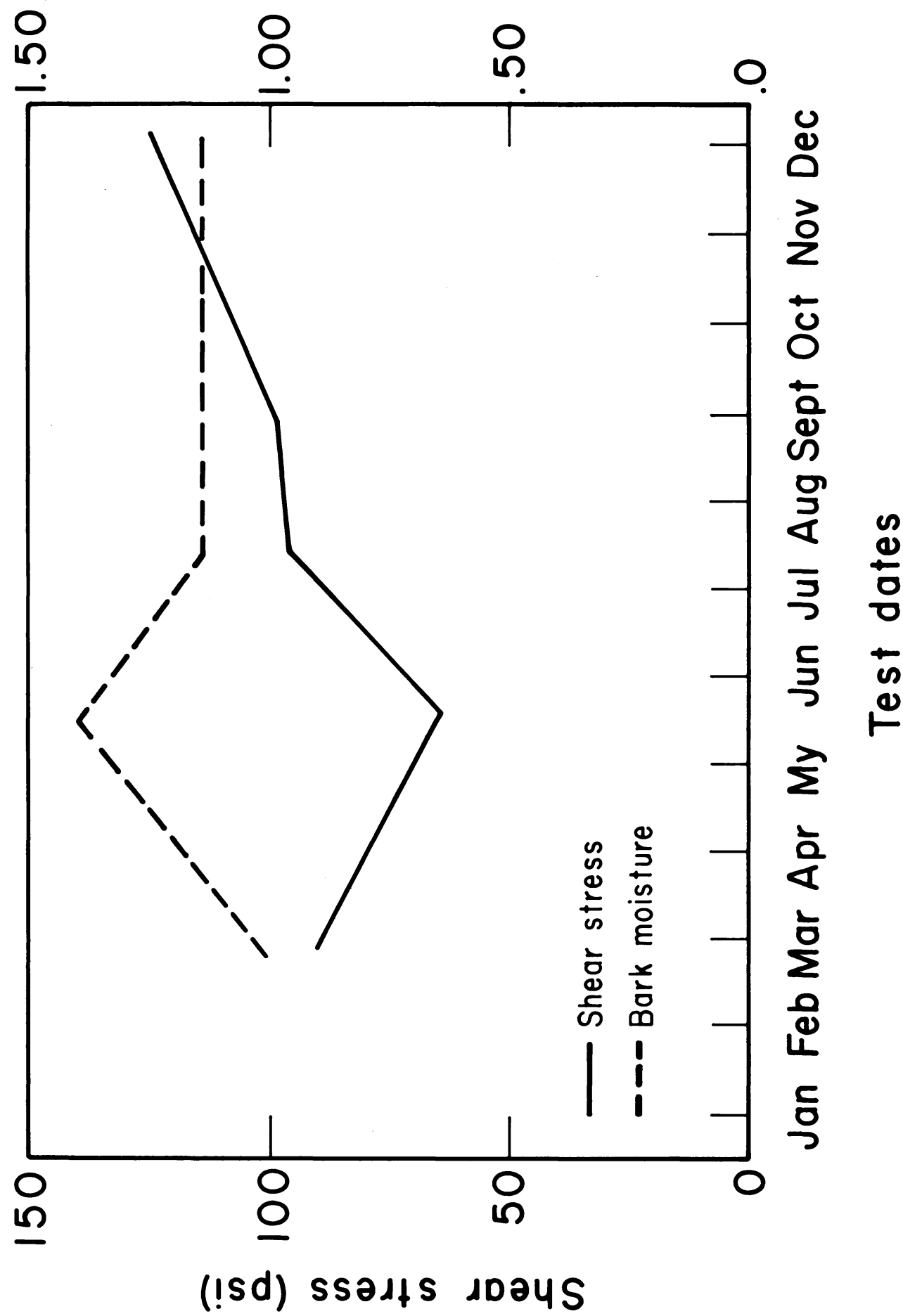

Fig. 11. Seasonal variations of longitudinal shear strength and bark moisture of French prunes. 
ary-March. In late May, bark moisture reached its highest level for the season.

By comparing results given in tables 3 and 4 it can be seen that longitudinal shear strength of bark is generally inversely related to bark moisture. Figure 11 illustrates this point for French prunes. When moisture in prune trees reached its highest level of the season in May, shear strength was at its lowest level. When bark moisture was at its lowest level (November to January) shear strength was at its maximum.

\section{Tangential strength as related to tree age}

Field tests to evaluate the influence of tree age on tangential strength were conducted in two grower orchards. One, in the Yuba City area, had trees aged $6,7,11,13$, and 17 years. The other, in the Oroville area, had trees aged 4, 6 , 9 , and 23 years. The Yuba City orchard was tested on two dates, and the Oroville orchard on one date. Six measurements were made of total strength and two of cambium strength for each tree age; each measurement was on a separate tree.

In the Yuba City orchard, both total and cambium strength were lowest for the 6-year-old trees, and increased for the 7-, 11-, and 13-year-old, but were slightly lower again for the 17-year-old. Reduction in strength for the 17-yearold trees can probably be attributed to some past growing condition or a variability in the soil in the test area. Both test dates showed consistent results. Tests in the Oroville area revealed an increase in total strength of about 25 per cent from 4 to 9 years of age (285 to $365 \mathrm{psi}$ ) but only a slight increase from 9 to 23 years old. There was a great difference in bark strength in trees of the same age in the two areas; the bark of the trees at Oroville was approximately 100 psi stronger than bark in the Yuba City orchard. The Yuba City orchard was irrigated more liberally, which could account for part of this difference (although bark moisture in the orchard was not measured).

\section{Bark stress-strain measurements}

Figure 13 shows longitudinal stressstrain diagrams for four laboratory tests on almond and two tests on olive. The change in slope of the curves in the early part of loading might be due to a hardening effect caused by initial compression of the bark fibers by the radial force. Strain in the mid-range of the curves is primarily bark strain caused largely by angular displacement. The stiffening effect evident before failure may be due to the cambial zone being subjected to nearly pure shear after completion of the angular bark strain phase. Figure 13 is included to show that strain does not increase rapidly near failure and that failure is abrupt.

\section{Bark tensile strength}

A few tests on 6-year-old almond bark showed a strength of 96 pounds per inch of width for a force longitudinal to the direction of the limb, and of 60 pounds per inch for a force tangential to the limb. During these tests it was observed that the inner bark provided most of the strength for longitudinal loading, and that the outer bark provided most of the strength for tangential loading. Due to fiber orientation the outer bark fails at about 10 per cent of the ultimate longitudinal tension, and makes a clean break across the strip. Similar failure occurs in the inner bark during tangential testing.

Similar tests on 6-year-old prunes yielded strengths of 80 pounds per inch and 25 pounds per inch for longitudinal and tangential forces, respectively. The fact that almond bark is more than twice as strong as prune bark in a direction tangential to the limb is thought to be the result of outer bark fibers aligning tangentially for almond bark and longitudinally for prune bark. 


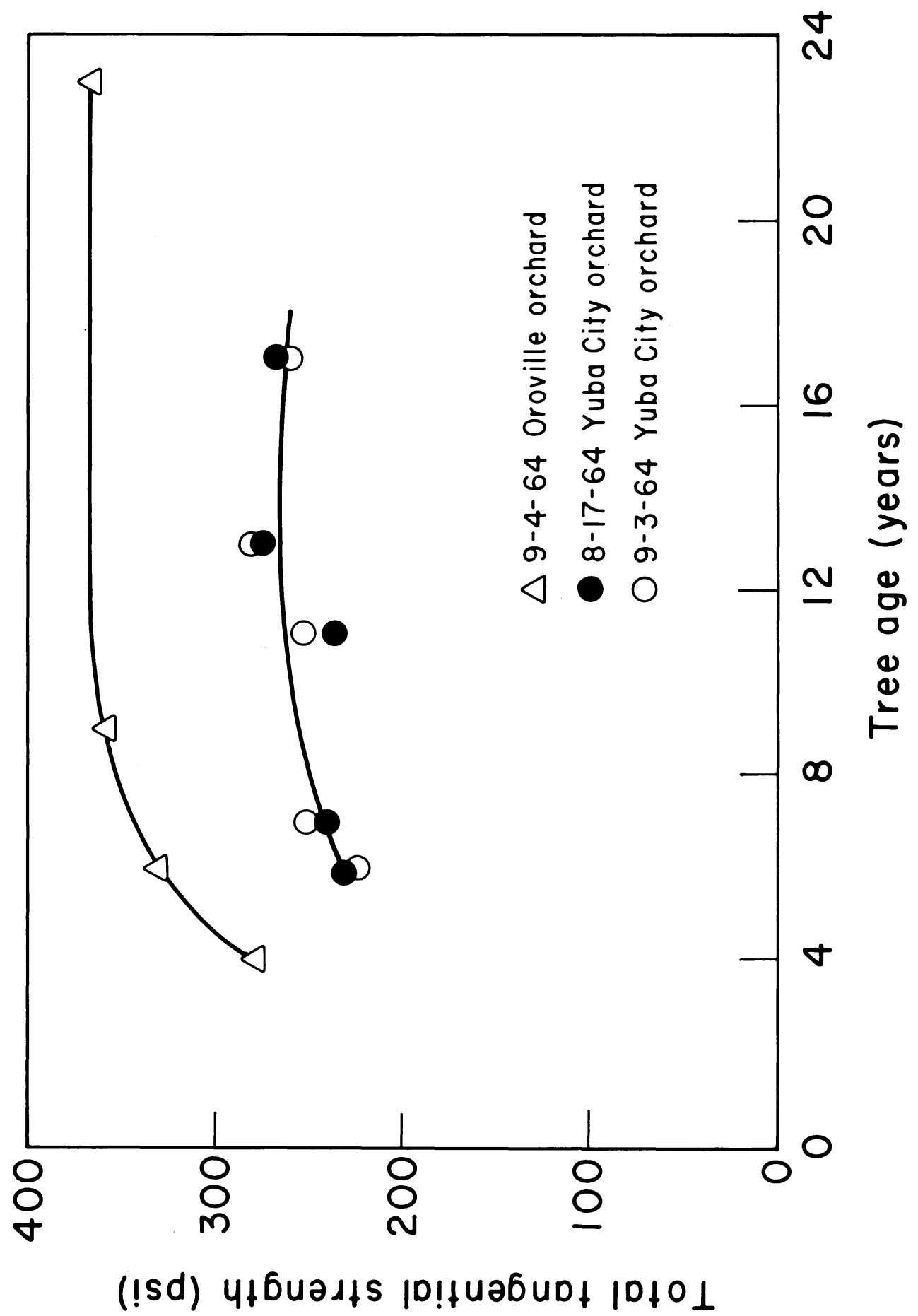

Fig. 12. Effect of tree age on total tangential shear strength of French prunes in two orchards. 


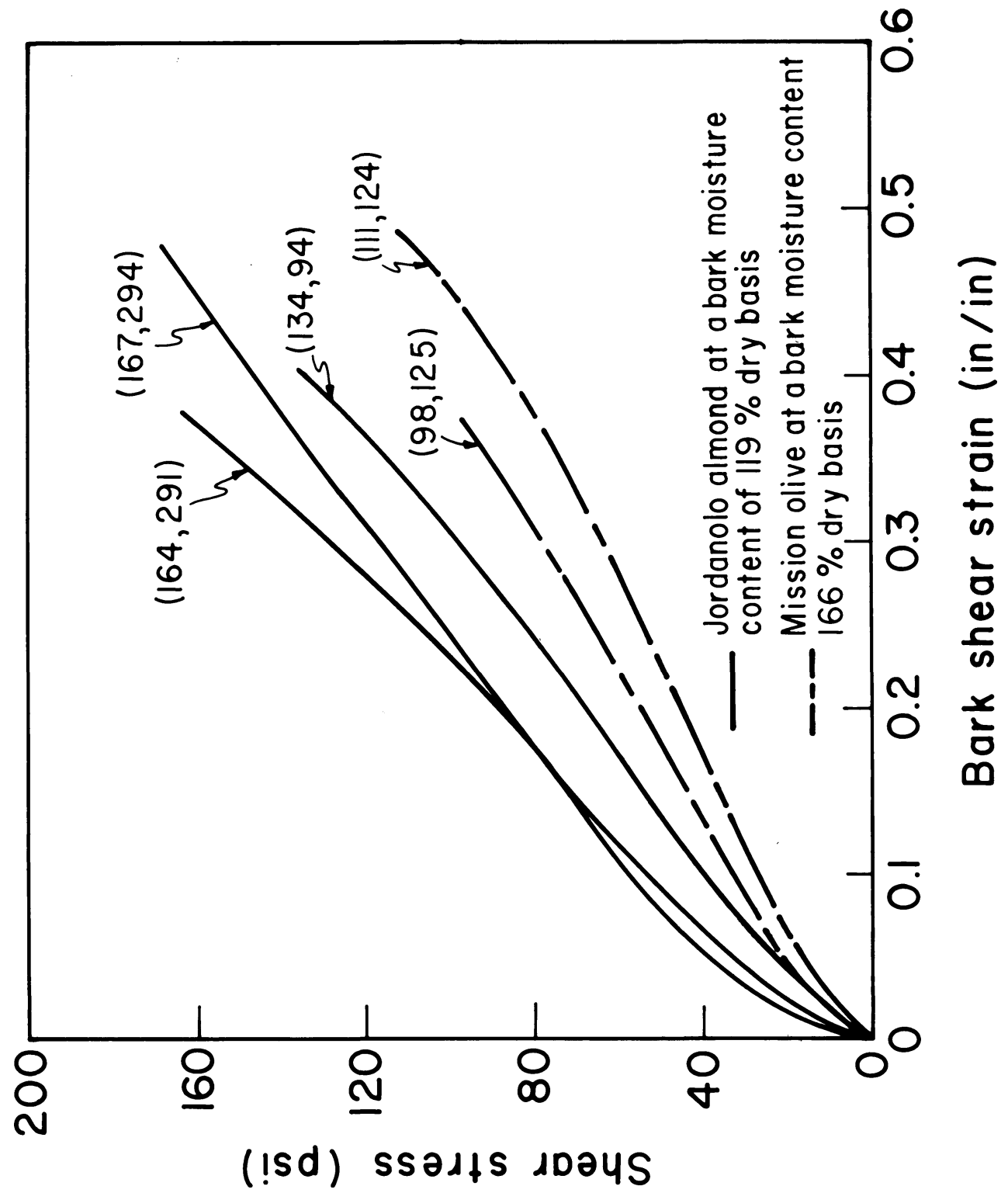

Fig. 13. Stress-strain relationship of bark subjected to longitudinal shear force. The first number adjacent to each line gives the longitudinal shear strength of the sample; the second number gives the radial stress at failure.

\section{CONCLUSIONS}

Tests indicate that injury to bark and infection of these injuries by Ceratocystis canker are associated with the magnitude and direction of stresses applied to the bark. In general, the bark can withstand about 3 to 4 times as much stress applied radially as when stress is applied longitudinally or tangentially to the limb. Maximum radial stress was in the range of 500 to 1000 psi.

Bark moisture content had a sub- 
stantial effect on the force required to shear bark from a fruit tree limb, and this effect was most pronounced at higher radial stresses. High moistures were associated with low shear strength, and low moistures with high shear strength. Higher moistures were also found to lower the point at which radial stress played a dominant role in shear failure.

Shear strength was also affected by radial stress. This is particularly important in the design of shaker clamps because shear stress cannot appear in the absence of radial stress. For high moisture conditions of bark, shear strength decreased with increase in radial stress; at low moisture, shear strength increased with increase in radial stress. This suggests that some critical moisture condition may exist above which shear strength is decreased by increase of radial stress. It is evident that proper scheduling of irrigations prior to harvest may increase the bark strength, and may therefore decrease the probability of bark damage associated with the use of tree shakers. Shear strength values vary with variety and species, and differences in shear strength values and shapes of strength curves change during periods of cambial activity, rest, and dormancy.

Test data for determining relationships between shear strength and bark moisture-content were quite variable, but it may be possible to decrease this variation by performing all tests, measurements, and dryings in a controlled environment room. Such a facility was not available for these tests.

Considering both seasonal variations and the effect of bark moisture, it can be concluded that bark strength is directly related to cessation of cambial activity and the associated shrinkage of cambium cells. An active cambium is conducive to bark damage caused by tree-shaker clamps.

\section{ACKNOWLEDGMENTS}

Appreciation is expressed to the following organizations and individuals for their cooperation and assistance: to the California Prune Advisory Board, the Cling Peach Advisory Board, and the Almond Industry for financial assistance; to Dr. J. E. DeVay and Bruce Parkinson for performing inoculation tests, and other technical assistance; to Dr. Kiyoto Uriu, Dr. Del- bert Henderson, and David Chaney for technical assistance; and finally to Jim Rumsey and Clarence Wong for general assistance and collection of data. Part of this paper is based in part on the second author's unpublished Master of Science Thesis, Some Factors Affecting the Longitudinal Shear of Bark from Fruit Tree Limbs, University of California, Davis. 


\section{LITERATURE CITED}

Adrian, P. A. and R. B. Fridley.

1964. Shaker-clamp design as related to allowable stresses of tree bark. Transactions of the ASAE 7(3) : 232-37.

DeVay, J. E., H. English, F. L. Lukezic, and H. J. O'Reilly

1960. Mallet wound canker of almond trees. California Agriculture 14(8) : 8-9.

DeVay, J. E., F. L. Lukezic, H. English, K. Uriu, and C. J. Hansen

1962. Ceratocystis canker on prunes and apricots. California Agriculture 16(1) : 2-3.

DeVay, J. E., F. L. Lukezic, W. H. English, W. J. Moller, and B. W. Parkinson

1965. Controlling Ceratocystis canker of stone fruit trees. California Agriculture 19(10) : 2-4.

Esau, Katherine

1948. Phloem structure in the grapevine, and its seasonal changes. Hilgardia, University of California, 18 (5) : 217-96.

Evert, Ray Franklin

1958. Phloem structure in Pyrus communis L., and its seasonal changes. Ph.D. Thesis (Botany), University of California, Davis.

Priestley, J. H.

1930. Studies in the physiology of cambial activity III. The seasonal activity of the cambium. New Phytologist, 29: 316-54.

Schneider, Henry

1952. The phloem of the sweet orange tree trunk and the seasonal production of xylem and phloem. Hilgardia, University of California 21(12) : 331-66.

To simplify the information, it is sometimes necessary to use trade names of products or equipment. No endorsement of named products is intended nor is criticism implied of similar products not mentioned. 


The journal HILGARDIA is published at irregular intervals, in volumes of about 650 to $\mathbf{7 0 0}$ pages. The number of issues per volume varies.

Single copies of any issue may be obtained free, as long as the supply lasts; please request by volume and issue number from:

$$
\begin{aligned}
& \text { Agricultural Publications } \\
& \text { University Hall } \\
& \text { University of California } \\
& \text { Berkeley, California } \mathbf{9 4 7 2 0}
\end{aligned}
$$

The limit to nonresidents of California is 10 separate titles. The limit to California residents is $\mathbf{2 0}$ separate titles.

The journal will be sent regularly to libraries, schools, or institutions in one of the following ways:

1. In exchange for similar published material on research.

2. As a gift to qualified repository libraries only.

3. On a subscription basis $-\$ 7.50$ a year paid in advance. All subscriptions will be started with the first number issued during a calendar year. Subscribers starting during any given year will be sent back numbers to the first of that year and will be billed for the ensuing year the following January. Make checks or money orders payable to The Regents of The University of California; send payment with order to Agricultural Publications at above address. 